\title{
A STUDY OF FACTORS AFFECTING THE LEVEL OF HAPPINESS AMONGST PRACTITIONERS OF YOGA, AEROBICS AND WALKING DURING CORONA LOCKDOWN
}

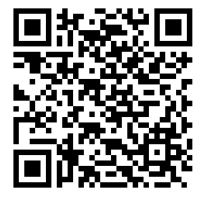

\author{
Vikram Singh 1, Pragyendu Yaduvanshi 2, Karan Singh 3 区 (iD) \\ ${ }^{1}$ Assistant Director, PE, JNU New Delhi-110067, India \\ ${ }^{2}$ Assistant Professor, Sri Aurobindo College (E), University of Delhi, New Delhi, Indiia \\ ${ }^{3}$ Applied Psychology (Hons), Sri Aurobindo College (E), University of Delhi, India
}

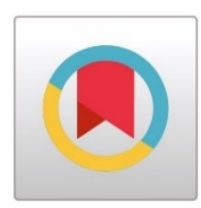

D0I: https://doi.org/10.29121/granthaalayah.v9.i3.2021.3829

Article Type: Case Study

Article Citation: Vikram Singh, Pragyendu Yaduvanshi, and Karan Singh. (2021). A STUDY OF FACTORS AFFECTING THE LEVEL OF HAPPINESS AMONGST

PRACTITIONERS OF YOGA, AEROBICS AND WALKING DURING CORONA LOCKDOWN. International Journal of Research -

GRANTHAALAYAH, 9(3), 338-346. https://doi.org/10.29121/granthaa layah.v9.i3.2021.3829

Received Date: 16 March 2021

Accepted Date: 31 March 2021

Keywords:

Age

Happiness

Yoga

Aerobics

Walking

\section{ABSTRACT}

Fitness and Yoga has been the focus of studies in recent decades for the not only the general well-being but also a therapeutic modality for mental stress, obesity, and other lifestyle disorders. Individual studies indicate positive effects of exercises like aerobics, walking and yoga under covid-19 lockdown conditions, suggesting that they can be used as nonpharmacological and as non-invasive interventions or as a supplement to drug therapy for the prevention and treatment of various mental and physical conditions. 120 moderately active healthy males (59) and females (61) volunteered to participate in the survey study with the aim to study the level of happiness and related variables age, body mass index, level of education and choice of physical activity of the participants. Oxford Happiness Questionnaire (OHQ) developed by psychologists Michael Argyle and Peter Hills at Oxford University was used to collect data. Results showed that there was no statistically significant difference in the choice of activity out of the three namely: aerobics, yoga and walking to stay fit and healthy. The level of happiness was found to be better for those who spent a greater number of years in school/college/university and another finding was that the level happiness was lower amongst the participants who were of more age as compared to the ones who were of lesser age. There was a significant difference in the level of happiness amongst the walkers, aerobic practitioners and yoga practitioners. It was not possible however to point out exactly the magnitude of difference between the three groups because the data was non-parametric. No gender differences were observed amongst males and females on level of happiness on activities chosen by the participants (aerobics, yoga and walking) to stay fit and healthy. Significant differences amongst the participants were observed amongst the underweight, normal weight and overweight participants.

\section{INTRODUCTION}

India is a country of a large population of youth. As per the World Population Prospects: The 2015 revision Population Database [1], United Nations Population, in 2010, the population of people in the youth age group of 1534 years in Asia was $33.93 \%$ of the total population and is predicted to decline to $31.54 \%$ by the end of 2020 . The

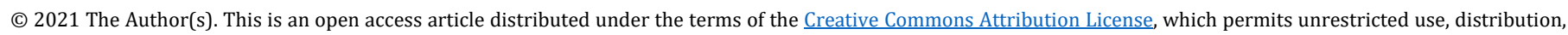
and reproduction in any medium, provided the original author and source are credited. 
same document says that the share of the youth population (15-34 years) in India in 2010 was $35.11 \%$ and is predicted to reduce to $34.46 \%$ by 2020 and might decline to $32.26 \%$ by 2030 . Lifestyle disorders are the two major causes of concern not only in developed countries but also in developing nations like India. Dementia, stress, degenerative joint diseases, and respiratory infections are increasingly becoming common health issues affecting the children, youth, and the elderly with almost equal magnitude. Various government and non-government bodies are having a tough time in handling the lifestyle-related cases vis a vis quality of life, especially during lockdown due to COVID-19. Different online and offline means and methods are being adopted to improve and activate people's lifestyles. They include yoga, exercises, massage, stretching exercises, treadmill walking, etc. Yoga is an ancient Indian science that enhances physical, mental, social, and spiritual health. By its peculiarities, asana and pranayama, Yoga found its special existence not only in India but also in countries like China, Japan USA, etc. Indoor yoga as a more effective alternative to outdoor exercise has become a compulsion and not a choice during the covid-19 lockdown in India. Research works on yoga and other happiness-inducing options were conducted to a certain extent in India. It's necessary to show that yoga isn't just an exercise system, but it has many mental health benefits. In youth, it can be wisely applied to improve happiness levels thereby promoting quality of life. Research is needed to understand yoga's action mechanism in improving happiness and its other psycho-physiological correlates.

Stress, tension, anxiety are major factors affecting a person's mental health and happiness regardless of age, gender, and education level. A low level of happiness can be an indicator of the onset of the Presentation of stress may vary from the fight-to-flight phenomenon. Chronic stress is the primary cause of many physical and mental disorders. Yoga has been used extensively in stress management.

In studying happiness related changes, age, education level, body mass index, and choice of activity are some important factors to take into account. Though there is no age limit for the yoga practice, the effect can vary according to age. Population-based studies are required to study the effect of yoga on age to develop a suitable model for different groups as per specific needs.

\section{MATERIALS AND METHODS}

\subsection{SUBJECTS}

In this study 120 normal healthy volunteers of both the genders (59 males and 61 females), interested in the study and who were physically active at least for 5 days a week, 30 minutes a day in doing activities of their choice for the last at least 6 months were selected. They were divided into two groups according to gender (males, female), into 3 groups as per choice of activity (yoga, aerobics, walking), body mass index (BMI)-3 categories (underweight, normal body weight and overweight) as per the international criteria-based BMI as follows: <18.5 for underweight, 18.5-24.9 for normal-weight, 25.0-29.9 for overweight..Mean age of the group was 24.5 and age range was 20 to 31 years.

\subsection{INCLUSION CRITERIA}

No previous medical issue

Moderately active at least for 5 days a week, 30 minutes a day in doing activities of their choice for the last at least 6 months

\subsection{EXCLUSION CRITERIA}

Below 20 years of age and above 31 years of age

Elite sports persons

Obese persons

\subsection{ETHICAL CLEARANCE-NOT APPLICABLE}

Informed written consent was taken from all the participants to volunteer for demographic measurements and fill up the questionnaire. 
A Study of Factors Affecting the Level of Happiness Amongst Practitioners of Yoga, Aerobics and Walking During Corona Lockdown

\subsection{DESIGN OF THE STUDY}

It is a survey study to assess the level of happiness amongst the moderately active persons living in Delhi, NCR. Total 120 (61 females and 59 males) were assessed on happiness scale.

\subsection{METHODS}

Selected individuals were asked to submit a written consent from and were willing to participate in the study. After collecting their demographic details (age, gender, height, body mass, body mass index, level of education, choice of activity), the subjects were then given the Oxford Happiness Questionnaire (OHQ) developed by psychologists Michael Argyle and Peter Hills at Oxford University. This is a survey study on the participants' happiness. Happiness Quotient score of the participants is compared to analyze the differences and to see.

- If the data is normally distributed or not

- If the choice of activity will be same for all participants or not.

- To find out the correlation between level of happiness and the three independent variables namely age and education level and choice of activity.

The research hypotheses $\left((\mathrm{Ho})=\right.$ null hypothesis, $\left(\mathrm{H}_{1}\right)=$ alternate hypothesis $\left.)\right)$ :

1) Choice of activity will be same for all the participants (Ho)

2) There will be no significant relationship between age and level of happiness (Ho)

3) There will be no significant relationship between choice of activity and level of happiness (Ho)

4) There will be no significant relationship between education level and level of happiness (Ho)

5) Alternate hypothesis $\left(\mathrm{H}_{1}\right)$ will be accepted in case of rejection of $\mathrm{Ho}$ as above.

\subsection{ASSESSMENT CRITERIA}

For the purpose of this study, happiness is defined as a mental or emotional state of wellbeing marked by positive or pleasant emotions that also get reflected in positive actions. The oxford Happiness Questionnaire was developed by Michael Argyle and Peter Hills of Oxford Brookes University, and originally published in 2002 in the Journal of Personality and Individual Differences.[2] It is a measure of subjective well-being or happiness. This is a self-reporting questionnaire containing 29 items that are marked from 1 to 6 on the extent to which the participant agrees or disagrees with the statement. Some of the statements are reversed to nullify participants 'biases.

\subsection{STATISTICAL ANALYSIS}

Obtained data was analyzed statistically using non-parametric tests-Chi-square test and Spearman rank order correlation to test the hypothesis to further assess the difference between the groups. SPSS version 25 was being used to perform statistical analysis. Level of significance was set at $P<0.05$.

\section{RESULTS}

Table1: Descriptive Statistics

\begin{tabular}{|c|c|c|c|}
\hline & $\mathrm{N}$ & Mean & Std. Deviation \\
\hline Age (in years) & 120 & 24.52 & 3.060 \\
\hline Body Mass Index $\left(\mathrm{kg} / \mathrm{m}^{2}\right)$ & 120 & 23.2153 & 2.40779 \\
\hline Level of Happiness (on a scale of 1 to 6 ) & 120 & 4.05 & 1.346 \\
\hline $\begin{array}{l}\text { Level of education (total number of years of completed education in } \\
\text { school or college/university) }\end{array}$ & 120 & 15.85 & 2.421 \\
\hline Valid N (listwise) & 120 & & \\
\hline
\end{tabular}


Table-1 shows descriptive statistics of $(\mathrm{N}=120)$ participants on mean and standard deviation of age, body mass index (BMI), level of happiness and level of education. Age (Mean=24.52 \pm 3.06$)$, body mass index (Mean $=12.21 \pm$ 2.40 ), level of happiness ( $4.05 \pm 1.34$ ), level of education (Mean $=15.85 \pm 2.42$ )

Table2: Tests of Normality for age, body mass index, level of education and level of happiness

\section{a. Lilliefors Significance Correction}

\begin{tabular}{|c|c|c|c|c|}
\hline \multirow[t]{2}{*}{ Variable } & \multicolumn{3}{|c|}{ Kolmogorov-Smirnova } & Shapiro-Wilk \\
\hline & Statistic & $\mathrm{df}$ & Sig. & $\begin{array}{l}\text { Statistic df } \text { Sig. } \\
\text { Stis }\end{array}$ \\
\hline Age & .120 & 120 & .000 & \begin{tabular}{|l|l|}
.942 & 120.000 \\
\end{tabular} \\
\hline Body Mass Index & .161 & 120 & .000 & 120.000 \\
\hline Level of education (in years & .204 & 120 & .000 & 120.000 \\
\hline Level of Happiness & .193 & 120 & .000 & \begin{tabular}{|l|l|}
.910 & 120.000 \\
\end{tabular} \\
\hline
\end{tabular}

Table 2 shows the tests of normality of data. Null hypothesis was that the data will be normally distributed and alternate hypothesis was that the data will not be normally distributed. Since the data is large in number, we interpreted the Kolmogorov-Smirnov values. A Kolmogorov-Smirnov test in table-2 indicates that neither of the four independent variables namely age, body mass index, level of education (years of completed education) follows a normal distribution

- $\quad$ Age variable does not follow a normal distribution, $D(120)=0.12, p=0.000$.

- Body Mass Index (BMI) variable does not follow a normal distribution, $D(120)=0.16, p=0.000$.

- Level of education (in years) variable does not follow a normal distribution, $D(120)=0.20, p=0.000$.

- Level of happiness variable does not follow a normal distribution, $D(120)=0.19, p=0.000$.

- Null hypothesis $\left(\mathrm{H}_{0}\right)$ was that the age, BMI, level of education and level of happiness will be normally distributed has been rejected and therefore, the alternate hypothesis has been accepted.

$\mathrm{H}_{0}$ : Data are sampled from a normal distribution. Otherwise, alternate hypothesis $\left(\mathrm{H}_{1}\right)$ will be accepted.

Table 3: Descriptive statistics showing frequencies of choice of activity of participants

\begin{tabular}{|c|c|c|}
\hline Activity Choice & Counts & \% of Total \\
\hline Aerobics & 47 & $39.2 \%$ \\
\hline Walking & 36 & $30.0 \%$ \\
\hline Yoga & 37 & $30.8 \%$ \\
\hline N (total) & 120 (Missing $=0$ ) & \\
\hline Shapiro-Wilk & $\mathrm{P}<.001$ & \\
\hline
\end{tabular}

As we can see from the Shapiro-Wilk test value in Table-3, p-value $<.001$, and so we reject the null hypothesis and conclude with $99 \%$ confidence that the data are not normally distributed (alternate hypothesis is accepted)

Hypothesis: The null hypothesis $\left(\mathrm{H}_{0}\right)$ was that the choice of activity will be same for all the participants. Alternate hypothesis $\left(\mathrm{H}_{1}\right)$ will otherwise be accepted.

Table 4: Activity choice wise proportion Test (N Outcomes) and $\chi^{2}$ Goodness of Fit test for the 3 choice of activities made by the participants

\begin{tabular}{|c|c|c|c|}
\hline \multicolumn{4}{|c|}{ Proportions - activity choice } \\
\hline Activity name & & Count & Proportion \\
\hline Aerobics & Observed & 47 & 0.392 \\
\hline & Expected & 40 & 0.333 \\
\hline Walking & Observed & 36 & 0.3 \\
\hline & Expected & 40 & 0.333 \\
\hline Yoga & Observed & 37 & 0.308 \\
\hline & Expected & 40 & 0.333 \\
\hline$\chi^{2}$ Goodness of Fit & $\boldsymbol{\chi}^{\mathbf{2}}=\mathbf{1 . 8 5}$ & $\mathrm{df}=2$ & $\mathrm{P}=0.397$ \\
\hline
\end{tabular}


The table 4 provides the actual result of the chi-square goodness-of-fit test. We can see from this table that our test statistic is statistically non-significant: $\chi^{2}(2)=1.85, p>.05$. Therefore, we accept the null hypothesis and conclude that there are statistically non-significant differences in the choice of activity, with people equally preferring the "aerobics" ( $N=47)$, walking $(\mathrm{N}=36)$ and Yoga $(\mathrm{N}=37)$.

Null hypothesis $\left(\mathrm{H}_{0}\right)$ was that there will not be significant relationship between age, level of education and level of happiness amongst the participants. Alternate hypothesis $\left(\mathrm{H}_{1}\right)$ otherwise will be accepted.

Table 5: Non-parametric (NP) correlations between level of education, level of happiness and age variables.

\begin{tabular}{|c|c|c|c|c|c|}
\hline \multicolumn{3}{|c|}{ NP Correlations } & Level of education (in & Level of & Age \\
\hline \multirow[t]{9}{*}{$\begin{array}{l}\text { Spearman's rho } \\
\left(\mathrm{r}_{\mathrm{s})}\right.\end{array}$} & \multirow[t]{3}{*}{$\begin{array}{c}\text { Level of education (in } \\
\text { years) }\end{array}$} & $\begin{array}{c}\text { Correlation } \\
\text { Coefficient }\end{array}$ & 1.000 & $.183^{*}$ & $385^{* *}$ \\
\hline & & Sig. (2-tailed) & . & .045 & .000 \\
\hline & & $\mathrm{N}$ & 120 & 120 & 120 \\
\hline & \multirow[t]{3}{*}{ Level of Happiness } & $\begin{array}{c}\text { Correlation } \\
\text { Coefficient }\end{array}$ & $.183^{*}$ & 1.000 & $.202^{-}$ \\
\hline & & Sig. (2-tailed) & .045 & . & .027 \\
\hline & & $\mathrm{N}$ & 120 & 120 & 120 \\
\hline & \multirow[t]{3}{*}{ Age } & $\begin{array}{c}\text { Correlation } \\
\text { Coefficient }\end{array}$ & $.385^{* *}$ & $-.202^{*}$ & 1.000 \\
\hline & & Sig. (2-tailed) & .000 & .027 & \\
\hline & & $\mathrm{N}$ & 120 & 120 & 120 \\
\hline
\end{tabular}

*. Correlation is significant at the 0.05 level (2-tailed).

**. Correlation is significant at the 0.01 level (2-tailed).

Table 5 shows non-parametric correlation with Spearman's rho was used because the data was not normally distributed. A Spearman's rank-order correlation was run to determine the relationship between 120 person's age, level of education and level of happiness.

1) There was a strong, positive correlation between age and level of education, which was statistically significant $\left(\mathrm{r}_{\mathrm{s}}=.385, \mathrm{p}=.000\right)$.

2) There was a strong, negative correlation between age and level of happiness, which was statistically significant ( $r s=-.202, \mathrm{p}=.027$ ).

3) There was a strong, positive correlation between level of education and level of happiness, which was statistically significant $\left(\mathrm{r}_{\mathrm{s}}=.183, \mathrm{p}=.045\right)$.

Table 6: Kruskal-Wallis Test

\begin{tabular}{|c|c|c|c|}
\hline \multicolumn{4}{|c|}{ Ranks } \\
\hline & Choice of act & $\mathrm{N}$ & Mean Rank \\
\hline Level of Happiness & Aerobics & 47 & 48.14 \\
\cline { 2 - 4 } & Walking & 36 & 55.24 \\
\cline { 2 - 4 } & Yoga & 37 & 81.32 \\
\cline { 2 - 4 } & Total & 120 & \\
\hline
\end{tabular}

Table 7: Test Statistics ${ }^{a, b}$

\begin{tabular}{|c|c|}
\hline & Level of Happiness \\
\hline Kruskal-Wallis H & 20.970 \\
\hline df & 2 \\
\hline Asymp. Sig. & .000 \\
\hline a. Kruskal Wallis Test \\
\hline \multicolumn{2}{|l|}{ b. Grouping Variable: Choice of act } \\
\hline
\end{tabular}


A Kruskal-Wallis $\mathrm{H}$ test (Table 6 and 7) showed that there was a statistically significant difference in level of happiness between the different activities being practiced by the participants, $\chi^{2}(2)=20.970, p=0.000$, with a mean rank happiness score of 48.14 for aerobics, 55.24 for walking and 81.32 for Yoga practitioners.

Table 8: Kruskal-Wallis Test

\begin{tabular}{|l|c|c|c|}
\hline \multicolumn{4}{|c|}{ Ranks } \\
\hline & Gender & $\mathrm{N}$ & Mean Rank \\
\hline Level of Happiness & Male & 59 & 61.09 \\
\cline { 2 - 4 } & Female & 61 & 59.93 \\
\cline { 2 - 4 } & Total & 120 & \\
\hline
\end{tabular}

Table 9: Test Statistics ${ }^{\mathrm{a}, \mathrm{b}}$

\begin{tabular}{|c|c|}
\hline & Level of Happiness \\
\hline Kruskal-Wallis H & .035 \\
\hline Df & 1 \\
\hline Asymp. Sig. & .851 \\
\hline a. Kruskal Wallis Test \\
\hline \multicolumn{2}{|l|}{ b. Grouping Variable: Gender } \\
\hline
\end{tabular}

A Kruskal-Wallis $\mathrm{H}$ test (Table-8 and 9) showed that there was a statistically non-significant difference in level of happiness between the male and female participants, $\chi^{2}(1)=.035, p=0.851$, with a mean rank happiness score of 61.09 for males and 59.93 for females.

Table 10: Kruskal-Wallis Test

\begin{tabular}{|c|c|c|c|}
\hline \multicolumn{4}{|c|}{ Ranks } \\
\hline \multirow{4}{*}{ Level of Happiness } & Body Mass Index & N & Mean Rank \\
\cline { 2 - 4 } & Underweight & 2 & 10.50 \\
\cline { 2 - 4 } & Normal Weight Range & 84 & 58.42 \\
\cline { 2 - 4 } & Overweight & 34 & 68.57 \\
\cline { 2 - 4 } & Total & 120 & \\
\hline
\end{tabular}

Table 11: Test Statistics ${ }^{a, b}$

\begin{tabular}{|c|c|}
\hline & Level of Happiness \\
\hline Kruskal-Wallis H & 6.560 \\
\hline df & 2 \\
\hline Asymp. Sig. & .038 \\
\hline a. Kruskal Wallis Test \\
\hline b. Grouping Variable: Body Mass Index \\
\hline
\end{tabular}

A Kruskal-Wallis $\mathrm{H}$ test (Table 10 and 11) showed that there was a statistically significant difference in level of happiness between the underweight, normal weight range and overweight participants, $\chi^{2}(2)=6.560, p=0.038$, with a mean rank happiness score of 10.50 for underweight, 58.42 for normal weight range and 68.57 for overweight participants.

\section{DISCUSSION}

Happiness is a good variable and can be interpreted for several purposes, for example in terms of country economics, democracy, equality, health, housing, social security, education, family life and other personal characteristics. In such a situation, happiness is defined as reflecting long-term, not just occasional or everyday emotions.[3] 
Since the data violated the normality assumption, therefore non-parametric correlations between level of education, level of happiness and age variables was being applied. Significant positive correlation observed between age and level of education suggests that, as we grow old, there is a greater probability of attaining higher level of education as displayed by the subjects as the older subjects were found to have attended the formal system of education for a longer duration of time. Although this was not the primary objective of the present study, but just information to build up foreground for further observations about the participants and their variable analysis. Significant negative correlation between age and level of happiness suggests that, higher age was associated with low level of happiness in the subjects despite having spent more time in education system. The effect of age on happiness, as defined by positive and negative effect, was examined in a survey of 2,727 persons of a broad age range (25-74) conducted by the MacArthur Foundation Research Network on Successful Midlife Development. The ageaffect association was examined, controlling for a host of socio demographic, personality, and contextual influences. Among women, age was related to positive affect nonlinearly but was unrelated to negative effect. Among men, age interacted with 2 key variables in predicting affect: extraversion and marital status. These findings lend support to recent life span theories of emotion and indicate that personality, contextual, and socio demographic variables, as well as their interactions, are all needed to fully understand the age-effect relationship.[4]

A study [5] on "Subjective happiness and health behavior among a sample of university students in India" tried to establish the associations between health behaviors and happiness in an Asian (Indian) population in a crosssectional survey to happiness and health behavior among a sample of 800 randomly selected university students taking non health (mainly engineering and sciences) undergraduate courses at Gitam University, Visakhapatnam in India. The students were 541 (67.6\%) males and 259 (32.4\%) females in the age range of 17 to 20 years (M age 18.2 years, $\mathrm{SD}=1.0$ ). Their major finding was that better social support, better personal mastery, normal sleep duration, no current tobacco use, and eating breakfast daily or almost daily were associated with happiness. The findings partially confirmed the association between happiness and several health behaviors mediated by social factors. They suggested that their study findings can be utilized in programs designed to improve overall well-being of university students in India.

A significant positive correlation between level of education and level of happiness suggests that, higher the level of education, better the level of happiness in the subjects since higher the number scored out of 6 , more the happiness that has been observed in the present study.

Happiness is one of the variables that are related to academic achievement. According to research, the people who have a high sense of happiness are more active in academic performance and progress of higher education.[6]

A Kruskal-Wallis H test (Table-6 and 7) showed that there was a statistically significant difference in level of happiness between the different activities being practiced by the participants. A study [7] entitled "YOGA VERSUS AEROBIC EXERCISE IN MENTAL WELL-BEING" evaluated and compared yoga and aerobic exercise in their effects on promoting mental well-being in college students. There was a total of 334 participants enrolled in either a yoga or aerobic type activity course. It was found that there were no significant differences between activity type and better overall mental well-being indicated by the Subjective Happiness Scale.

In a 2019 study [8], the researchers used self-administered questionnaires for 79 (median age of 24 years) first year medical students at the St. George's University of London medical programme delivered by the University of Nicosia Medical School in Cyprus. Physical activity was assessed using the International Physical Activity Questionnaire Short Form and happiness was assessed using the Short Depression Happiness Scale. Results suggested that the total amount of physical activity performed, as well as level of happiness, did not significantly differ between genders. Although the effects of BMI and perceived health on happiness are still largely unknown, research shows that overweight is significantly related with lower self-assessments of personal happiness in social groups where overweight is less common [9]. This finding indicates that the socio-cultural environment may mediate the effects of BMI and perceived health on happiness. Some studies show a correlation between obesity and depression, further depending on the severity of the obesity (Larsson et al., 2002; Onyike et al., 2003; Groessl et al., 2004).[10],[11],[12] A Kruskal-Wallis H test (Table-10 and 11) in this study showed that there was a statistically significant difference in level of happiness between the underweight, normal weight range and overweight participants 
Vikram Singh, Pragyendu Yaduvanshi, and Karan Singh

\section{CONCLUSION}

All the participants equally preferred aerobics, yoga and walking as their choice of activity to stay fit and healthy. As regards level of happiness, it was better for those having higher qualifications but the level happiness was lower amongst the participants with higher age. There was a significant difference in level of happiness amongst the walkers, aerobic practitioners and yoga practitioners. It was not possible however to point out exactly the magnitude of difference between the three groups because the data was non-parametric. The males and females were equally happy with whatever they were doing (out of the three activities namely aerobics, yoga and walking) to stay fit and healthy. It was also seen that there was a significant difference amongst the participants who were either underweight, normal weight or overweight.

\section{SOURCES OF FUNDING}

This research received no specific grant from any funding agency in the public, commercial, or not-for-profit sectors.

\section{CONFLICT OF INTEREST}

The author have declared that no competing interests exist.

\section{ACKNOWLEDGMENT}

None.

\section{REFERENCES}

[1] (Laaksonen, S. A Research Note: Happiness by Age is More Complex than U-Shaped. J Happiness Stud 19, 471482 (2018). https://doi.org/10.1007/s10902-016-9830-1).

[2] (Lyubomirsky, S. \& Lepper, H. S. (1999). A measure of subjective happiness: Preliminary reliability and construct validation. Social Indicators Research, 46, 137-155.

[3] (Mroczek, D. K., \& Kolarz, C. M. (1998). The effect of age on positive and negative affect: A developmental perspective on happiness. Journal of Personality and Social Psychology, 75(5), 1333-1349. https://doi.org/10.1037/0022-3514.75.5.1333)

[4] (Subjective happiness and health behavior among a sample of university students in India Authors: Peltzer, Karl; Pengpid, Supa Source: Social Behavior and Personality: an international journal, Volume 41, Number 6, 2013, pp. 1045-1056(12) Publisher: Scientific Journal Publishers, DOI: https://doi.org/10.2224/sbp.2013.41.6.1045)

[5] Baumeister, R. F., \& Tice, D. M. (1984). Role of self-presentation and choice in cognitive dissonance under forced compliance: Necessary or sufficient causes? Journal of Personality and Social Psychology, 46, 5-13.

[6] Fisher, J.J., Kaitelidou, D. \& Samoutis, G. Happiness and physical activity levels of first year medical students studying in Cyprus: a cross-sectional survey. BMC Med Educ 19, 475 (2019). https://doi.org/10.1186/s12909-019-1790-9.

[7] Groessl, E., R. Kaplan, E. Barret-Connor and Th. Ganiats: 2004, 'Body Mass Index and the quality of well-being in a community of older adults', American Journal of Preventive Medicine 26(2), pp. 126-129.

[8] Hills, P., \& Argyle, M. (2002). The Oxford Happiness Questionnaire: a compact scale for the measurement of psychological well-being. Personality and Individual Differences, 33, 1073-1082

[9] Larsson, U., J. Karlsson and M. Sullivan: 2002, 'Impact of overweight and obesity on health-related quality of life - a Swedish population study', International Journal of Obesity 26, pp. 417-424.

[10] Methodology of the United Nations Population Estimates and Projections

Citation: United Nations, Department of Economic and Social Affairs, Population Division (2015). World Population Prospects: The 2015 Revision, Methodology of the United Nations Population Estimates and Projections. ESA/P/WP.242. 
[11] Onyike, C., R. Crum, H. Lee, C. Lyketsos and W. Eaton: 2003, 'Is obesity associated with major depression? Results from the Third National Health and Nutrition and Examination Survey', American Journal of Epidemiology 158, pp. 1139-1147

[12] Pinhey, T.K., D.H. Rubinstein and R.S. Colfax: 1997, 'Overweight and happiness: The reflected self-appraisal hypothesis reconsidered', Social Science Quarterly 78(3), pp. 747-755. 